\title{
Content of Traditional Education on Human Sexual Relationships Among the Ameru Women of Kenya
}

\author{
Karambu A. Maigallo \\ Department of Social Sciences, Chuka University, P.O. Box 109, 60600, Chuka-Kenya \\ Dr. Caroline Mucece Kithinji \\ Department of Humanities, Chuka University, P.O. Box 109, 60600, Chuka-Kenya
}

\begin{abstract}
1.1 Abstract
This study hypothesises that the traditional education on human relationship among the Ameru women would be the remedy for marital dissatisfaction and instability in Meru County. There is a decline in marital satisfaction and stability in Meru County as manifested by increase in marital violence and divorce which has led to stress and depression among married people. The study adopted an ethnographic research design. . Sub constructs of content of knowledge on human relationships studied included relationship within families, love and romantic relationships, marriage as a lifetime commitment and raising children. Data was collected from oral and secondary sources. A total of 80 respondents from various age groups participated in the study. Data from oral sources were corroborated with data from secondary sources. The major finding of this study was that the traditional Meru Community had an organized content of sexuality education that focused on marital satisfaction and marital stability hence families were more cohesive and stable. The study recommends an intergration of Ameru traditional content on human relationships in the school curriculum.
\end{abstract} Keywords: Traditional Education, Sexual Relationships, Kenya

DOI: $10.7176 / \mathrm{JEP} / 10-30-13$

Publication date:October $31^{\text {st }} 2019$

\subsection{Introduction}

Education on human sexual relationships is different for other studies because human sexuality is surrounded by a vast array of taboos, fears, prejudices and hypocrisy (Strong et-al, 2005). Sexuality is not only linked to intimacy and pleasure but also to shame, guilty and discomfort (LaHaye, 2005). Despite the ambivalence people still want to learn the correct aspects of human sexual relationships (Haward-Barr, More, Weiss \& Jobli, 2011).

The Changing technology, access to information on the Internet, greater awareness on none heterosexual identities, relationships, families and significant shift in meanings and experiences of childhood requires a more open and complex discussion with children on sexuality issues if they are to become competent, informed and responsible citizens (Robinson, 2014).

A good understand of one's sexuality allows individuals express affection and appreciation for themselves and their spouses (Pangman, 2000), and help them continue to be Intimate and passionate in their marriages (Langer, 2009). Education on human relationships in Traditional African Communities began in childhood but great emphasis to sexuality education was at initiation. Knowledge on human relationships among the Tanzanian communities entailed fundamental lessons about sexual expression itself and the range of socio-economic skills, roles and responsibilities demanded. In other words, the ethnic communities in Tanzania educated their children about sex in the holistic context. Education at initiation entailed fundamental lessons about sexual expression itself, a range of social economic skills, roles and responsibilities demanded by the community from a man or a woman (Marah, 2006).

The Meru used initiation period to educate their children about sexuality in a rounded context about life, preparing them for life (Nkanatha \& Karuri, 2014). The education for the girls was differentiated from that of the boys in accordance with the roles each sex was expected to play for the reminder of their adult lives (Nkanatha \& Karuri, 2014). However Nkanatha and Karuri (2014) did not establish the content of education on 
human relationships taught at initiation it role in enhancing marital satisfaction and stability. The formal school system and Christianity led to abandonment and distortion of the traditional initiation rites that functioned as agents of sexuality education.

It is therefore possible that people get knowledge on human relationship from media and peers all, which can give inappropriate knowledge. This raises a concern similar to Mbiti (1989) who stated that sex education was being gathered and disseminated by fellow young people and partisan mass media that is often a mixture of truth, myths, ignorance, guesswork, and jokes. Mbiti further alleged that schools and universities in modern Africa are perhaps centers of greater ignorance in matters of human sexual relationships such that young people go through school knowing how to dissect frogs how to establish a family (Mbiti, 1991). The findings by Mbiti were being manifested in Meru County as established by Kithinji (2013). Kithinji reported that people in Meru County were walking in and out of marriages yet the the Meru community was known for stable marriages that songwriters wrote songs in praise of Meru women for their endurance in marriages. This was the basis in which this study set out to establish how the traditional content of knowledge on human relationship among the Ameru women was used to enhance marital satisfaction and stability in Meru County.

\subsection{Objective}

To establish the content of traditional education on human sexual relationships among the Ameru women and how it was used to enhance marital satisfaction and stability in Meru County.

\subsection{Research Design}

This study is an Ethnographic Research Design. An Ethnographic Research is where a researcher studies what happens in a community as lived and practiced by the people in order to investigate a little understood phenomena (Oso \& Onen, 2011). Ethnographic Research Design was suitable for this study because human sexual relationships and marital satisfaction are issues that affects people and can be best understood if researched from the people affected in their natural settings.

\subsection{Sample Size}

Data was collected from 80 married people. Among the married people, 50 people were randomly sampled to participate in Focus Group Discussions while 30, who were from the oldest age group, were interviewed as Sexuality educators and counsellors.

\subsection{Location of the Study}

The study was conducted in Meru County. Meru County is the home of the Ameru. There are 5 sub-ethnic groups of Meru living in Meru County namely, the Igoji, the Miutine, the Imenti, the Tigania and the Igembe. These 5 sub-ethnic groups are believed to be the original sub-goups of Meru before the British colonialists merged them with the other four - the Tharaka, the Chuka, the Mwimbi and the Muthambi for administrative purposes. The latter four groups live in Tharaka-Nithi County of Kenya and share a similar culture with the other sub-ethnic groups of the Ameru living in Meru County.

\subsection{Research Instruments}

Data was collected using interview schedules and Focus Discussions Group (FDGs).

\subsection{Ethical Considerations}

This study was be guided by the ethical principles of psychological code of conduct in conducting research as indicated in the American Psychological Association (APA, 2002).

\subsection{Findings of the study}

The Social system of the Ameru was organized in age groups within which there were age sets. There are eight age groups namely Michubu, Ratanya, Lubetaa, Miriti, Guantai, Gichunge, Kiramunya and Ithalii. Within the each age group, there were three age sets beginning with Ndinguri, followed by Kobia then finally Kaberia. 
Meru women adopted their husband age groups. During the period of the study, there were 7 living age groups with the oldest being the Michubu age group and the youngest being the Kiramunya age group.

The Meru Community had unwritten curriculum on education on human relationships that was delivered at initiation. The curriculum had an entry which was the actual day of the cut (initiation). The education took place in a secluded house at initiation. There were trainers who were sponsors at initiation, peers and members of an age group slightly older than the initiates as well as the grandmothers' to the initiates. There were methodologies that involved lectures, group discussions and practical demonstrations. There was an evaluation and grading where the initiate would be asked questions in relationship to what was taught and any correct answer or demonstration. Rewards for correct answers were beads known as "Njuthi" which were to be produced and shown to the mother-in-law when the girl got married. There was a graduation which took place on the day the initiate was getting out of seclusion. There was a follow up where one was required to repeat what they had been taught to the younger initiates. In case a person gave the wrong information, they were punished by beating or ridicule. Follow up occurred throughout life so in case one went against or acted contrary to what was taught at initiation, they were fined or faced other forms of punishment. The objective of the education on human relationship was to build stable and united families which were meant to lead to a socially functional community.

\subsection{Content of Traditional Education on Human Relationship among the Ameru Women and it Role in Promoting Marital Satisfaction and Stability in Meru County.}

Sub constructs of content of knowledge on human relationships studied included relationship within families, relationship with friends, love and romantic relationships, marriage as a lifetime commitment and raising children.

\subsubsection{Content of Traditional Education on Relationship within families among the Ameru Women and it Role in Promoting Marital Satisfaction in Meru County}

Parent taught their children how to relate within families. They were taught to respect each other. Roles were allocated in families based on gender to avoid too much closeness between brothers and sisters. This was in order to discourage incest. Among the Michube age-group, boys were circumcised and became Morans 'Murani'. The morans went to live in a common house with other boys until they got married. Their role was to defend the community from enemies.

. A moran never went to plough in the shamba. That was a responsibility delegated to women and girl. The girls and women were also expected cook and do other household chores. Old men and young boys herded animals. The old men were also expected to be part of the village/clan court. They mostly settled land disputes and conflicts related to marriage.

Women were required to feed the morans in the common house. If a woman did not feed the young men and had a son who was a moran, the son would be fined a bull. Wives were also required to cook and grind for everybody in the family. The herders had to meet food ready once they arrived from the fields. Among the Ratanya age-group women were taught to make sure that every child had their own gourd to store the gruel. This is what children would take until supper was ready. The boys even carried the gourd along with them as they went herding. At no time was this gourd expected to lack gruel or fermented milk. Women were taught to make sure that their husbands also had their own gourds which were have gruel at all times. A group of women of Ratanya age-groups said that the gourds had been replaced by kettles and thermoses. One woman said.

Any woman who wants happiness in her marriage should make sure that there is a thermos reserved for her husband which should always have a drink in it. She should also reserve a specific serving dish for her husband and make sure there is always food in it for a husband to eat once he returns home.

Another women added,

The pride of any woman should be in cooking and feeding her husband. This makes him happy and contented.

She continued to say.

The secret of any satisfactory marriage, is for the wife to make sure that her husband always well fed and is sexually satisfied.

All people were taught never to have sexual relationships with members of their families. Even romantic relationships or discussions between members of the same family were considered an abomination. 
Young people of the Michubu, Miriti and Lubetaa age-groups were discouraged from having sexual affairs so as to avoid a 'bad breed of children'. One woman said,

'Children from incest relationships do not expand a generation. It leads to inbreeding which leads to genetic issues that can clear a family just like what happens in animals.'

This was agreed by many respondents.

Circumcised Girls would not to enter into their fathers houses to discourage incest. Circumcised girls never talked to their fathers directly. If a man was found to be talking to their daughter, they were fined a bull to be eaten by his age mates. Since childhood, girls were taught to listen to and respect men. Their mothers and grandmothers insisted to them that it was a must for a wife to listen to her husband and obey him.

A husband had his house and the wife had her house. This encouraged respect for personal space. Wives were taught never to touch her husband things if she was not invited to do so. If a husband came with yams at home and did not give the wife. The wife would not touch them. Even when the wife made gruel for her husband and stored it gruel in his gourd, she would no longer touch that gourd until the husband handed it back to her.

The Beijing Conference of 1994 was taken as an affront to marriages where women were encouraged to compete with men and rebel from men. Most men felt threatened by the empowered woman who 'knew her rights'. These were the age groups where most women began going to the universities and other institutions of higher learning. Those who drop out of school at lower levels left Meru and went to work as house girls and house boys in other parts of the country majorly in Nairobi. This led to people getting a lot of information from their peers and the media which led to mixed knowledge on how the spouses should relate to each other within the family. There was therefore no properly organized content or method of delivery of knowledge on relationship within families among respondents of the Guantai and Gichunge age group. Every respondent had their own version of how people should relate within families. This led to increase in conflict in marriages and marital instability in Meru.

\subsubsection{Content of Traditional Education on Love and Romantic Relationships among the Ameru Women and it Role in Promoting Marital Satisfaction in Meru County}

Knowledge on romantic relationship and dating began during puberty among the Ratanya, Lubetaa and Miriti age-groups. It was taught by older boys and girls who were still uncircumcised during a developmental stage Gukurua/Kigumi. They were told that if they were talking to members of the opposite sex and see elder, they were supposed to cut the discussion short and each of them walks away in a different direction. This is because if an elder found two young people of the opposite sexes standing and chatting on the road, they would punish the two young people by caning. Men had also been taught not to expose their affection to women they were in love with in presence of children or older people. It they did so, one would be fined a bull.

Instilling knowledge on romantic relationship and dating was advanced when both girls and boys were in circumcised and in seclusion. This was done by and older persons under the supervision of a person allocated by the parents of the young person to act as a sponsor at initiations known as "Mugwati." A sponsor at initiation was not to be of the same age-group with the parents of the initiate. It was often someone from an immediate older age-group or younger age-group than the parents and respected within the community. Peers also discussed issues of romantic relationships themselves. They encouraged each other to look for girls to be potential wives. The ideal girls for marriage were those who would love and respect their parents. Though boys were keen on dating and marrying, what mattered most was the ability of the girl to respect elders.

Girls were taught to be proud and "play hard to get". One respondent of the Miriti age-group narrated this: We were taught to be proud. We would not greet boys on the road. Even when they whistled at us, we would not turn our heads. Even if a boy hit us on the road, we would not turn or talk to them. Boys were supposed to admire us from a distance. We were taught to walk in company of small children or old women so that the boys would not bother us on the road.

Boys and girls got involved romantically with each other with the focus of getting married. Whereas peers encouraged each other to engage in sexual intercourse, parents and grandparents discouraged sexual intercourse among young people before there was an official engagement.

Young people were taught to engage in constructive activities when dating. For example, a boy dating a girl would be expected to organize a group of boys and girls to till the suitors' fathers land. Girls were taught not to entertain boys during the day so as not to do what they had planned to do. This was emphasized in a song.

Nthaka cieya rukiiri, 
ingi cieya ugoro

Nthaka, ukeenda niiriku

Niira, cieya na ugoro

Nicio, itiutera ngugi

This translated to mean, if young men come looking for you in the morning, and others come in the evening, chose those that come in the eventing because they are the ones who will not derail your work or waste your time.

Girls expected that if a boy wanted a serious relationship with them, he would visit the girls' home. It was expected that once the boy got at the girls home, they should cough at the gate. The girls were taught that they should only receive such a guest at their home if the mother prompted them to go and great the guest. She was expected to resist his advances. But if the boy visited the home severally the girl would accept the relationship. Once the girl accepted to be in a relationship with the boy, the courtship would officially begin. The boy would ask his parents to visit the girls' home.

Before starting official marriage negotiations, girls were required to inform their parents to do backgrounds check of the boy's family. They checked if there was a history of madness, epilepsy or witchcraft in the prospective in-laws. They also checked how disciplined and hard working the mother and aunts were. They also confirmed from elders if there was any blood relationship between the couples. They would only marry on if the blood relationship had gone past to the $8^{\text {th }}$ generation.

If the parents did their search and visited the girls' and no objection to their son marrying the girl, Among the Tigania and Igembe, they would take 'Miraa' and among the Imenti they would take "Kiruthu" a local brew to the girls' parents and marriage negotiations would commence. Once the miraa was accepted, the boy's parents would then take a lot of gifts to the girls' parents

\subsubsection{Content of Traditional Education on Marriage as a Lifetime Commitment among the Ameru Women and it Role in Promoting Marital Satisfaction in Meru County}

Young people of the Michubu age-group were taught that marriage was a life-time commitment. All content related to marriage as a lifetime commitment was taught to both boys and girls during seclusion after circumcision. They were discouraged from marrying from other tribes except from the Maasai. They believed that if one married a Maasai girl they would bring wealth in form of cows and also would enhance peace between the two communities. Among the Imenti, the bride price had to be paid for the marriage to be acknowledged by the two families. This is because bride-price was considered a sign that the boy's family were committed to marrying and protecting the girl.

Clarification on the issue of bride price was sought from Njuri Ncheke elders. The elders informed that paying of bride price was a form of appreciation to the girls' parents. They concurred with each other that he most essential items for the bride price included:

Miraa for the Tigania and Igembe /Kiruthu (Traditional Alcohol Brew) for the Imenti to open the negotiations. A he goat to be eaten by the father, a she-sheep for the mother, a drum of honey for the elders, $a$ heifer and a bull.

They added that unlike in the past, parents of the Guantai and Gichunge age-groups had become greedy and demanded so much from the sons-in-law making life so hard for the marriages. He cited examples where parents were demanding to be refunded the fees paid for their daughters leading to frustration and that is why men of the Guantai and Gichunge age-group are rebelling against paying the bride price. One Njuri Ncheke elder noted that unlike in the previous generations where paying of bride price was done by all members of the clan, young men of the Guantai and Gichunge age groups are made to raise the items for bride price alone because many parents have absconded the duty of getting wives for their sons.

Meru women of Michubu, Ratanya, Lubetaa and Miriti age-groups were taught to respect themselves first. Women were all taught to listen and obey their husbands. They were also taught not to taste alcohol even when brewed alcohol but would not taste. This is because it was believed that if they took alcohol they would misbehave. Women were also taught not to sit and drink with men. All this changed in the 1980s when women become educated. Men were taught to respect their wives and be kind to them.

Among the Michubu, Ratanya and Lubetaa age-groups, girls were taught that they should not beat men at any point of their lives. This they were taught by their grandparents and other older women. They were also taught 
not to have sexual affairs with 'Giciaro'. Parents often did not talk to their children about sexuality. They often sent emissaries who often were people respected by the family and community to talk to their children.

Girls and boys were taught from childhood, that marriage was a lifetime commitment that one did not have to get into marriage without following the due process. Among the Ratanya age group, once the consent was granted, it would be time for the girl to be circumcised. Girls would never be married before being circumcised and the girls would not be circumcised without a suitor. The girl would dance to her various relatives' homes. In any home she danced she would be given a goat and other gifts by her relatives. Once the girl felt that she had enough gifts, she would tell her suitor who would then, together with his parents organize for the girl to be circumcised. Once the girl was circumcised, she would stay in seclusion for about one year. During seclusion she would be taught how to relate to her husband and other people in the community. This was done by Mugwati and other women. The education was organized in three sessions known as Kugwata Monki, Gutuma Into and Kwaana Mucii.

During 'Gwakia Mwoonki' the girl would be told that a husband has to be pampered. They were also told not to sleep on their children's or husband's clothes. They were also told that a woman does not get to bed when food is cooking. They were told that people do not have sex with a child in bed. If there was a child in bed, they were to spread sacks on the floor and have sex on the floor. They were told that they would abstain from sex for six months once they got a child. They were also expected to have sex in darkeness until the first child is born.

Her husband was a man who had been honoured and respected by her parents and that is why they had accepted that she marries him. She was therefore expected to respect him, obey him and never insult or hit him. She had to cook and feed her husband.

"You will have to cook and feed your husband. If you do not cook and feed him he will not take care of you and your children"

They women were taught to feed their husbands before feeding the children. They were expected to make gruel for their husbands. So any time they ground, they had to have a separate guard for their husbands. This is what the husband would share with the peers any time the peers visited. It was an abomination for guest to visit the home and left without being fed. During this ceremony, women would demonstrate to the girl how to serve food and gruel according to the Meru traditions. This was a sign that women had sat and talked to the girl on how to behave in marriage. It was meant to instil discipline on the girl. It was expected that once the girl had been marriage she would show girls how to serve the food. This was inherited from one generation to another. If a woman appointed to demonstrate to a girl how to serve food did it wrongly, she would be fined seven pots of local brew.

Women were taught that it was ultimate that they respect their husbands. If a wife by any chance insulted her husband or was rude to her husband and her husband reported her to the clan, he would be fined seven pots of traditional brew known as 'Maroa' and a he-goats to be paid by her biological father. If a husband mistreated his wife, or hit his wife in presence of children he would be fined a bull to be eaten by Njuri Ncheke elders and the clan. He would also be required to provide enough yams to feed his age mates as a part of the fine. And receive a thorough beating from the clan elders. Women were educated that if their husbands annoyed them, they would go home to their biological parents and wait for the husband to go and plead with her parents before going back to the matrimonial home.

The next session for the women was "Gutuma into". Here they made basket with beads and the girl was given. A girl who had had an abortion would not 'Gutuma Into'. This basket would be produced when the girl was wedding to prove that women sat with her and educated her on how married women behave. On this occassion the girls were taught by women that:

Women of the Michubu, Ratanya, Lubetaa, and Miriti age-groups were taught that they must respect their husbands and never to hit them. They were also taught to respect their mothers-in-law and fathers-in-law to avoid conflict in their marriage. They were also told that they needed to respect and love their neighbours and all children within the community. They were told not to quarrel with their husbands in presence of children or other people. If they did so, they would be fined 'Mirongo Ithatu'. Women were also taught to take care of their mother-in-law and fathers-in-law. They were encouraged that any time they cooked food they needed to have a calabash to serve the in-laws. In reciprocation, the mother-in-law also brought food the the daughters-in-law any time she cooked. 
Women of the Meru community would not accept to be married as second wives without the consent of the first wife. This is because the Meru traditions required that even if there was disatisfaction in marriage, the first wife would have to consent that here husband marries a second wife. If one got married as a second wife without the consent of the first wife, the clan chased you away from the home because it was understood that the new woman was interfering negatively in an existing marriage. Participants in a focus group alluded that they had chased a woman from their villaged in 2004 who had been married without the consent of the first wife.

The dissatisfaction in marriages has been blamed on the introduction of school system and Christianity in Kenya. Among the respondents there was a woman of the Ratanya age-group one of the earliest women to be a Christian. She reported the following.

I did my catechism in the church when I was a young girl. As we approached marriage, we were required to take our prospective husbands to the priest for veting whether they would be good husbands. I took my husband to church and he had ot undergo catechism for two years in order for him to qualify to marry me. We were taught that marriage is a lifetime commitment, a contract that was not to be broken. In the church, were were told that the woman was the pillar of a satisfactory marriage. It was emphasized that a woman builds her home with her mouth. We were not to disrespect our husbands, talk rudely to them or beat them. We were told that anything we owned belonged to us and our husbands. We were taught to wash his clothes, cook for him and make sure he is sexually satisfied.

To follow up the discussion, the researcher asked the men who were also an early Christian converts what they knew about love. They reported that they were taught to love and respect their wives, provide for them and make sure they were sexually satisfied. However, Lubetaa age-group complained.

Men and Women of the Guantai and Gichunge age-groups are lost. They are neither Christians nor Africans. We do not know where they receive the notion that they should compete with each other in marriages. You find them insulting and beating each other on the road. Even when elders warn them they do not listen. We do not know where this generation is ending too. We no longer have marriages; we have people living together who often walk out on each other over small differences.

\subsubsection{Content of Traditional Education on Raising Children among the Ameru Women and it Role in Promoting Marital Satisfaction in Meru County}

The Ameru believed that children belong to the father who deligated the role of raising children to the mother. This did not mean the wife would raise the children alone. Children were taught to refer to all wives married to their father as their mothers. It was hard to distinguish children of different mothers in a homestead. One respondent reported that there were some elements of bad women who mistreated children. Every child fathered by a man whether in marriage or out of marriage also belonged to the biological father. No Meru girl or woman was allowed to get married and carry along with her a child from a previous relationship. $\mathrm{T}$

If a girl or woman had a child outside marriage, they would leave such a child with the parents of the girl and get married. Subsequently the parents of the girl would hand over the child to the biological father once the child was ready to be circumcised. Such a child would sometimes suffer if the maternal uncles did not accept the child or if the women married to the biological father were bad people who would mistreat the child. However, the community frowned against such behaviour and any woman who mistreated a child was considered an outcast.

Parenting was a joint responsibility and every member of the clan participated in raising a child. People were taught to punish a misbehaving child without consulting with the parents. No member of the community complained when another punished their child. People learnt how to raise children from childhood by observing how their parents and other members of the community raised their children. Once a woman got a child, an older aunt would be given the responsibility of helping her in bringing up the first child. Then women related to the young mother from both sides would organize visits to the new mother. During the visits they would bring gifts to the child and the mother then advise the mother on how to bring up the child. They also advised her on what food to eat so as to have enough milk to feed the baby and also regain her strength. Some of the foods she was advised to eat were yams, millet gruel and black beans among others.

Women were taught to ensure that they supplied enough food to feed a mother after delivery when she was not able to work. This helped reduce conflict between husbands and wives and led to satisfaction in marriage. Children belonged to the community so at no time did a husband and wife differ over the children.

However, the situation changed with the Guantai and Gichunge age groups. Members of this group went to school and learnt how to raise children from school. Those who did not learn from school learnt from observing 
what others were doing. Others reported that they learnt how to raise children from medics who advised them on how to feed their children. Above all, there was rise in human rights organizations that advocated for the rights of children. It was therefore not possible for members of the community to punish misbehaving child for the fear of being taken to court for "abusing the right of children. Hence raising children became an individual parents' affair that led to a dysfunctional society

\subsection{Conclusion}

Content of sexuality education was properly organized for the older generation. Those Ratanya age group, Lubetaa and Part of the Miriti age group reported that they had a program of teaching relationship with families, sexual behaviour, and sexual health at initiation at initiation, though it was not written. The age group slightly older acted as the sexuality educators who passed the content to the subsequent age group. These findings agree with Fadiman, (2012) that culture among was transmitted from the oldest generation to the youngest and that before embarking on any study in Meru Community about any aspect of the community, one was expected to begin from the oldest age group for they were considered the custodian of knowledge. The content had a method of delivery and there was an evaluation and a follow up. Knowledge on sexual relationships was delivered most by peers and sponsors at initiation. Grandmothers and other older women acted as the evaluators and "Njuthi" were the grades.

Sexuality relationships were seen a force that could lead to the distraction of the social system of the Ameru if not properly managed. Hence they incorporated the content of sexuality in all aspects of their daily life. Sexual relationships was governed by taboos and associated with divine power. These findings agree with Fuglesang, (1997) that sexuality was seen as a destructive force, out of control, it could endanger the whole society, cause emotional disturbances, spread physical infection, sow social discord, cause hatred and lead to envy so sexuality education was incorporated in all the activities of a young person.

The content also become more diverse as the age groups got younger. This is due to the breakdown of the Meru social system that was influenced by formal education, embracing of Christianity increase of media coverage ((Murah, 2006). Respondents of the Michubu, Ratanya, Lubetaa and Mung'tia age groups were very certain about content and age at which they received knowledge on human sexuality education. Contrariwise, the respondents of the Mburung'a and Gichunge age groups had to take time to remember the content and the age at which they got knowledge on human sexuality. These two younger generations also had diverse content of knowledge on human sexuality such that they could not agree during the FDGs.

The older respondents reported more satisfaction and stability in their marriages than the younger generations. This they associated with shift from the Ameru traditional education on the human relationships among women. It is therefore necessary for the Ministry of Education and Ministry of in Charge of Culture to work with the Kenya Institute of Curriculum Development to develop a curriculum that incorporates the Meru tradition education on human relationships to help reduce the dissatisfaction and instability in marriages in Meru County.

\subsection{References:}

Howard-Barr, E.M., Moore, M.J., \& Weiss, J.A. \& Jobli, E. (2011). Public opinion toward sexuality education: Findings among one south Florida county. American Journal of Sexuality Education, 6 (2), 1-16

Kithinji, C. M. (2013). Impact of Colonialism on Traditional African Marriages among the People of Igoji of Meru, 1907-2012. (Master's Thesis, Chuka University. Chuka. Kenya).

LaHaye, T \& B. (2005). The Act of Marriage: the Beauty of Sexual Love. Kenya. Nairobi. World Alive Publishers.

Langer, N. (2009). Late life Love and Intimacy. Educational Gerontology, 35 (8), 752-764. Retrieved from Online ERIC Database.

Mbiti, S.J. (1987). Love and Marriage in Africa ( $8^{\text {th }}$ Ed.). United Kingdom. Longman Group Limited

Nkanatha, J. K., \& Karuri, M. J. Female Genital Mutilation: Its Physical-Social Effects and Reasons for its persistence Among Communities. Research on Humanities and Social Sciences. ISSN (Paper)22245766 ISSN (Online) 2225-0484 (Online) 4 (28), 93-96

Oso, W.Y., \& Onen, D. (2011). Writing Research Proposal and Report: A Handbook for Beginning Researcher. Rsvdedn. Nairobi-Kenya. The Jomo Kenyatta Foundation.

Pangman, V., \& Sanguire, M. (2000). Sexuality and the Chronologically Ill Older Adults. A Social Justice Issue. Sexuality and Disability, 18 (1), 49. Retrieved online from Academic Research Database.

Robinson, K.H. (2014). Building Relationship Early: Educating Children on Gender Variance and Sexual Diversity. A Response to Damien Riggs. Contemporary Issues in Early Childhood. $\underline{\text { https://doi.org/10.2304/ciec.2014.14.1.81 }}$ 